\title{
Insights of project managers into the problems in project management
}

\author{
Peter Vincent Livesey \\ University of Technology Sydney, Australia
}

\begin{abstract}
A Delphi study using project managers who had managed projects in excess of $\$ 500$ million was used to confirm the significance and frequency of problems resulting from the nature of projects. Using the results obtained from the Delphi study a ranking of the problems experienced in these projects was obtained by calculating a Relative Importance Index. Additionally, the Delphi panel members were asked their views concerning the need for traditional project management skills (hard skills) and team management skills (soft skills) as project size increased from below $\$ 50$ million to over $\$ 500$ million. A substantial increase in the need for both skills was indicated with the increase in the need for soft skills being the most significant.
\end{abstract}

Keywords: Project management, Delphi study, project managers.

Paper type: Viewpoint

\section{Introduction}

A common definition of a project is "a temporary endeavour undertaken to create a unique product, service or result" (Project Management Project Management Institute (2013)). An alternative definition is "a set of diversely skilled people working together on a complex task over a limited time period" (Goodman and Goodman 1976, p.494). This latter definition has the advantage of emphasising that a team of individuals is involved in the joint endeavour. In addition to their temporary nature project teams are often geographically dispersed with teams involved in the design, management, procurement and construction functions in different locations. Furthermore, suppliers of key components are also often located in different countries or continents. This geographic dispersion can introduce its own problems.

The objective of this research was to deal with the process problems in project management rather than the outcomes such as cost and time overruns. To achieve this objective, it draws on the practical experience of project managers to confirm the magnitude and frequency of the project management problems identified from a consideration of the nature of projects, and to establish if the need for the various skill-sets changes with project size.

A literature review was therefore conducted with the aim of identifying the problems in project management literature that considered the nature of projects, i.e. their temporariness and potential geographic dispersion. The problems identified were then put to a panel consisting of project managers, for verification. The panel included project managers, $90 \%$ of whom had managed projects in the mining and infrastructure industries in excess of $\$ 1.0$ billion and all of

Copyright: Construction Economics and Building 2016. (C) 2016 Peter Vincent Livesey. This is an Open Access article distributed under the terms of the Creative Commons Attribution 4.0 Unported (CC BY 4.0) License (https://creativecommons.org/licenses/by/4.0/), allowing third parties to copy and redistribute the material in any medium or format and to remix, transform, and build upon the material for any purpose, even commercially, provided the original work is properly cited and states its license.

Citation: Livesey, P. V. 2016. Insights of project managers into the problems in project management, Construction Economics and Building, 16(1), 90-103. DOI: http://dx.doi.org/10.5130/AJCEB.v16i1.4600

Corresponding author: Peter Vincent Livesey; Email - petervincent.livesey@student.uts.edu.au

Publisher: University of Technology Sydney (UTS) ePress 
whom had managed projects over $\$ 0.5$ billion. Projects in the mining and infrastructure industries over $\$ 1$ billion in size are generally regarded as Mega projects (Flyvbjerg, 2014).

As indicated in the second definition above, projects involve a joint endeavour of people, and managing people involves a set of soft skills different from those more technical project management skills often referred to as PMBoK type skills (Bourne and Walker, 2004; Du, Johnson and Keil, 2004; Gonzalez, 2012; Pant and Baroudi, 2008; Thomas, George and Henning, 2012). The Delphi panel was also asked if, in their opinion, the need for these types of skills varied as project size increased.

\section{Literature review}

The need to recognise projects as temporary organisations was discussed by Packendorff (1995) and Lundin and Söderholm (1995). Turner and Müller (2003) also reviewed the nature of projects as a temporary organisation and found that this nature resulted in them being unique, having a high degree of uncertainty and requiring considerable flexibility by the project team having to deal with the various problems as they arose. They also identified that the requirement to progress the project in a specific timeframe would inevitably result in conflict with the various stakeholders and that these have to be resolved quickly in order for the project to move forward.

The uncertainty in projects is emphasised by Anantatmula (2010) who states "It is reasonable to assume that in project management, it is not if the plans will change, it is what will change, when, and by how much" (Anantatmula, 2010, p.19). This view is echoed by Sankaran and Agarwal (2013, p.6) who make the point "No two projects are identical. This implies that there is variability as well as variety in projects". Yeo (1993) also identified problems in project decisionmaking caused by the degree of uncertainty and ambiguity resulting from a lack of experience associated with the particular project's problems. Such problems can be due to organisational politics and/or the lack of relevant competencies to deal with the problems in the project team.

Druskat and Druskat (2012) argue that projects are: unique, temporary, progressively developed and involve team members who may come from different organisations, disciplines, cultures and remain together for a relatively short time. The authors suggest that the time element results in projects having a high degree of ambiguity, change, misunderstandings and miscommunications. The authors argue that these characteristics result in a need for rapid development of trust and that this need is increased when the background of the various stakeholder groups is considered. The importance of trust in contracting, particularly where contextual trust is prevalent, was also discussed by Winch (2010, p.96).

The impact of the uncertain and temporary nature of projects on the need to build trust was also a major finding in a study by Vierimaa (2013). Pryke and Smyth (2006) emphasised that the temporary nature of projects results in work being performed by team members who may or may not have worked together before and have different cultures, goals, beliefs and professional backgrounds. In a recent review Tyssen, Wald and Spieth (2013) identified the characteristics of temporary organisations presented in Table 1.

Hanisch and Wald (2014) considered the effect of complexity on temporary organisations by simplifying the Geraldi, Maylor and Williams (2011) model from five dimensions down to three. This model is summarised in Table 2.

\section{The impact of geographic location on the nature of projects}

As discussed, the different geographical locations of the teams involved in design, management, procurement and construction introduce additional problems in managing projects. Verburg, Bosch-Sijtsema and Vartiainen (2013) concluded that with geographically dispersed projects human factors were important. These factors included: 
- $\quad$ Project management style and competence

- Clarity of communication,

- Organisational support and

- $\quad$ The ability to develop trust.

Similar findings have been made by among others (Cramton and Webber, 2005; Hertel, Geister and Konradt, 2005; Lee-Kelley and Sankey, 2008; MacGregor, 2005; Montoya et al., 2009).

Table 1: Characteristics of temporary organisations developed from Tyssen, Wald and Spieth (2013)

\begin{tabular}{|l|l|}
\hline Characteristic & Potential consequences/challenges \\
\hline Temporariness & $\begin{array}{l}\text { Hampers development of positive relations (i.e. trust) and shared } \\
\text { values/norms. } \\
\text { Little or no experience of working with team members. }\end{array}$ \\
\hline $\begin{array}{l}\text { Missing/ambiguous } \\
\text { hierarchies }\end{array}$ & $\begin{array}{l}\text { Team members also report to line function manager, potential } \\
\text { "authority gap" of the project leader. } \\
\text { Inter-divisional and hierarchical collaboration hamper the team } \\
\text { building processes. } \\
\text { Team has to develop its own culture }\end{array}$ \\
\hline $\begin{array}{l}\text { Changing work teams } \\
\text { members }\end{array}$ & $\begin{array}{l}\text { Frequent changes allow for less time for beneficial group processes. } \\
\text { Difficulties in developing group cohesiveness and commitment. } \\
\text { Loss of trust previously developed between team members. }\end{array}$ \\
\hline $\begin{array}{l}\text { Unique project- } \\
\text { outcome }\end{array}$ & $\begin{array}{l}\text { Coordination and communication across disciplinary boundaries may } \\
\text { Individual knowledge not sufficient. } \\
\text { Limited recourse on experiences and routines. } \\
\text { Different professional backgrounds and cultures. } \\
\text { Competition for team members' time from other projects. }\end{array}$ \\
$\begin{array}{l}\text { Higher uncertainty and risk involved, creativity and autonomous } \\
\text { decision making required. } \\
\text { Unable to fall back on past experience, novel approaches often } \\
\text { required. } \\
\text { Coordination of professionals with different backgrounds. }\end{array}$ \\
\hline
\end{tabular}

Table 2: Effect of complexity on temporary organisations

\begin{tabular}{|l|l|l|}
\hline Dimension & Region of influence & Resulting needs and impacts \\
\hline $\begin{array}{l}\text { Structural complexity } \\
\text { including socio- } \\
\text { political complexity. }\end{array}$ & $\begin{array}{l}\text { Related to the number of project teams } \\
\text { and stakeholders involved in the } \\
\text { project. }\end{array}$ & $\begin{array}{l}\text { Need for greater co-ordination and } \\
\text { impacts on the development of trust, } \\
\text { group norms and knowledge } \\
\text { transfer. }\end{array}$ \\
\hline $\begin{array}{l}\text { Task complexity } \\
\text { (including } \\
\text { uncertainty). }\end{array}$ & $\begin{array}{l}\text { Relates to the uniqueness of the task } \\
\text { involved in the project. }\end{array}$ & $\begin{array}{l}\text { Results in a high need for } \\
\text { coordination requiring the sharing of } \\
\text { information and the processing of } \\
\text { knowledge. }\end{array}$ \\
\hline $\begin{array}{l}\text { Temporal } \\
\text { complexity/dynamics } \\
\text { (including pace). }\end{array}$ & $\begin{array}{l}\text { Considers the interdependence of tasks, } \\
\text { and the rate the task must be ber for } \\
\text { accomplished together with the possible } \\
\text { changes in the task and team members. }\end{array}$ & $\begin{array}{l}\text { Results in a high need fordination requiring the sharing of } \\
\text { information and the processing of } \\
\text { knowledge. }\end{array}$ \\
\hline
\end{tabular}




\section{Summary of the problems resulting from the nature of projects}

If the above works concerning the nature of projects are combined, the following resultant project characteristics can be identified:

1. Limited time duration for building a team, developing rapport with stakeholders, obtaining organisational support and building a working control system.

2. The temporary nature of the project team formed within time constraints results in the need to blend team members from different professional and social backgrounds, and understand and develop relationships with stakeholders who are also from different backgrounds. All of whom may be in different geographic locations.

3. The unique nature of the project requiring a solution in a condensed time frame puts pressure on the team to understand a particular project's requirements.

4. The frequent lack of definition, often due to time constraints, results in considerable ambiguity and changes to scope coupled with changes to team membership. This problem can be exacerbated by changes in the external environment.

5. Team structure and stakeholder organisation may change as the project progresses due to a variety of forces including: pressure from competing projects, identification of additional or redundant skill sets and natural attrition. All resulting issues must be solved within the given timeframe for the particular project.

6. Conflict results from communication problems, scope and personnel changes.

\section{Research method}

The original promoters of the Delphi technique (Dalkey and Helmer, 1963, p.458) defined the method as "a method used to obtain the most reliable consensus of opinion of a group of experts by a series of intensive questionnaires interspaced with controlled feedback". It, therefore, uses as its basis the assumption that a group opinion is superior to an individual opinion. The Delphi technique is described by Linstone and Turoff (1979). Its use as a research tool is discussed by Skulmoski, Hartman and Krahn (2007), its accuracy by Parente et al. (1984) and construction of the survey by Fink (2009). A comprehensive review of its history, alternative approaches, strengths and weaknesses is provided by Keeney, McKenna and Hasson (2010). It should be remembered that achieving consensus does not mean that the correct answers has been found, and should not be regarded as a replacement for a rigorous review of published literature or for original research.

A pilot Delphi study was based on the problems identified in the literature review. Results from this pilot study were used to develop an E-Delphi (SurveyMonkey). Selection of the panel was based on the following criteria:

Over twenty years of experience in the management of mining and infrastructure projects greater in size than $\$ 0.5$ billion. In practice, $90 \%$ of the panel members had managed projects in excess of $\$ 1$ billion. Participants had worked on projects acting either for the client or for contractors. The type of contract, EPCM, Lump, etc. on which the potential panel member had worked was not used as a selection criteria.

The above criteria resulted in the selection of a panel size of 25 members of which 22 responded to the issues raised in this study. The study was limited to 6 rounds to ensure maximum panel participation. To ensure anonymity the panel members were unaware of the identity of the other panel members or the author of any of the comments received during the course of the study.

The first question put to the panel was the study members' views on the importance of soft skills and PMBoK skills as the project size increased. The size selected for analysis was $<\$ 50$ million, $>\$ 50$ million and $<\$ 500$ million and $>\$ 500$ million. These size selections were based on the author's experience of the changes in the nature of the team work required for management as 
size changed ${ }^{\mathrm{i}}$. The panel was given the opportunity to comment and no adverse comments were received concerning these size selections.

The second set of questions was based on the literature review and asked the panel members to indicate their views on the impact of the following issues:

1. The limited time frame (i.e. having a set time period to achieve a set of defined objectives) of a project causes problems resulting from a need to quickly achieve the following:
a. Build a cohesive team.
b. Build trust within the team.
c. Develop rapport with stakeholders.
d. Develop a working control system.
e. Obtain organisational support.

2. Team members' diverse backgrounds (ethnic and experiential) and locations (e.g. concept design in Australia, detailed design in India, manufacturing in China, procurement run from Brisbane and a construction site in remote Australia) causes problems for team member management as a result of differences in:
a. Team members' personal goals and resultant personal agendas.
b. Team members' cultural backgrounds.
c. Team members' professional backgrounds.
d. Team members' communication needs.
e. Team members' different geographic locations.
f. Team members' native language differences.

3. 'The diverse stakeholders' backgrounds and locations causes problems for stakeholder management as a result of differences in:
a. Stakeholders' personal goals and resultant personal agendas.
b. Stakeholders 'cultural backgrounds.
c. Stakeholders' professional backgrounds.
d. Stakeholders' communication needs.
e. Stakeholders' different geographic locations.
f. Stakeholders' native language differences

4. The unique nature of each project (e.g. moving from a rail car project to a desalination plant and then to a tunnel project. Alternatively, the different problems encountered on technically similar projects such as different special interest groups creating their own unique problems) results in the following problems:
a. Understanding the issues involved in the particular project.
b. Managing internal stakeholder expectations.
c. Managing external stakeholder expectations.
d. The belief that you and the project team can solve the project's problems.

5. Ambiguity and change arising from:
a. Lack of a clearly defined project scope.
b. Scope changes as the project progresses.
c. Lack of information to make a fully informed decision.
d. Team member changes.
e. Unexpected and unforeseen events (e.g. subcontractor goes bankrupt).
f. Changes in the external environment (legislative, economic).

6. Changes in project team and stakeholder personnel resulting in:
a. Loss of a cohesive team
b. Loss of trust between team members. 
c. Loss of relationships with key stakeholders.

7. The conflicts (the disagreements that arise prior to a formal dispute) that arise during a project and their impact:
a. Those arising internally to the team.
b. Those arising externally to the team but internally to the parent organisation.
c. Those arising with subcontractors.
d. Those arising with other stakeholders

Whilst it is accepted that team members are, by definition, also stakeholders, it was decided to analyse them as a subset of stakeholders on the grounds that they have different motivations and relationships with the project manager than other stakeholders. For example, it is possible to remove a disgruntled member of the team from a project but a disgruntled stakeholder, who is not a team member, has to be dealt with on a continuing basis.

The panel members were given the opportunity to comment on the selection of questions for review and no comments challenging their inclusion was received. The panel members were also asked to express their opinion on the above questions using a five-point Likert-type scale (Likert, 1932) consisting of: very significant, significant, neutral, little significance, insignificant. In ranking the panel members' responses based on the Likert scale, the Relative Importance Index, as reviewed by Holt (2013) and also used in construction projects by other researchers (Gündüz, Nielsen and Özdemir, 2012; Kometa, Olomolaiye and Harris, 1994; Sambasivan and Soon, 2007), was used. The Relative Importance Index is based on the following formula:

Relative Importance Index $=\frac{\text { Sum of the scores given to the problem by panel respondents }}{\text { The maximum score that a problem could have received }}$

The panel members were also asked to indicate their view on the frequency of the occurrence of the problems on projects they had managed. The mean frequency of the occurrence of each problem was calculated by assuming the data in each frequency interval was uniformly distributed across the frequency interval. As a result the mid-point of the frequency intervals could be used in estimating the mean. The frequency intervals that were given to the panel and resultant interval midpoints used are presented in Table 3.

Table 3: Frequency intervals and associated mid-points

\begin{tabular}{|l|r|}
\hline \multicolumn{1}{|c|}{ Frequency interval } & Interval midpoint \\
\hline Very frequent occurrence $(>90 \%)$ & $95.0 \%$ \\
\hline Frequent occurrence $(<90 \%$ but $>75 \%)$ & $82.5 \%$ \\
\hline Average occurrence $(25 \%$ but $<75 \%)$ & $50.0 \%$ \\
\hline Infrequent occurrence $(<25 \%$ but $>10 \%)$ & $17.5 \%$ \\
\hline Seldom occurrence $(<10 \%)$ & $5.0 \%$ \\
\hline
\end{tabular}

The mean frequency (MF) was then calculated using the following formula:

$M F=\frac{\text { Sum of results in each frequency interval } X \text { the interval mid }- \text { point }}{\text { The number of data points }}$

The panel members' demographics are summarised in Table 4 (note $15 \%$ of panel members chose not to respond to the demographic questions). Allowing for some overlap the minimum total number of projects managed by panel members was 50 . 
Table 4: Delphi panel members' demographics

\begin{tabular}{|l|r|}
\hline \multicolumn{1}{|c|}{ Aspect } & Percentage \\
\hline Project involvement working for contractors & $34 \%$ \\
\hline Project involvement working for clients & $37 \%$ \\
\hline Project involvement working for consultants & $29 \%$ \\
\hline Degree qualified & $91 \%$ \\
\hline $\begin{array}{l}\text { Certified in project management (all certified members } \\
\text { were also degree qualified). }\end{array}$ & $19 \%$ \\
\hline Over 60 year of age & $50 \%$ \\
\hline 50-60 years of age & $40 \%$ \\
\hline 40-50 years of age & $10 \%$ \\
\hline Male & $95 \%$ \\
\hline
\end{tabular}

\section{Results and analysis}

\section{The relative importance of PMBoK and team management skills}

The panel was asked to rate the relative importance of PMBoK skills and team management skills for various sizes of projects. The results are summarised in Figure 1. As can be seen in Figure 1 the percentage allocated to important and very important by the panel changes from $86 \%$ for projects less than $\$ 50$ million to $100 \%$ for projects greater than $\$ 500$ million. If only the percentage allocated to very important is considered, then the change is more significant. In this case, for projects greater than $\$ 500$ million in size, $95 \%$ of the panel members rated team management skills as very important as opposed to $32 \%$ for projects less than $\$ 50$ million.

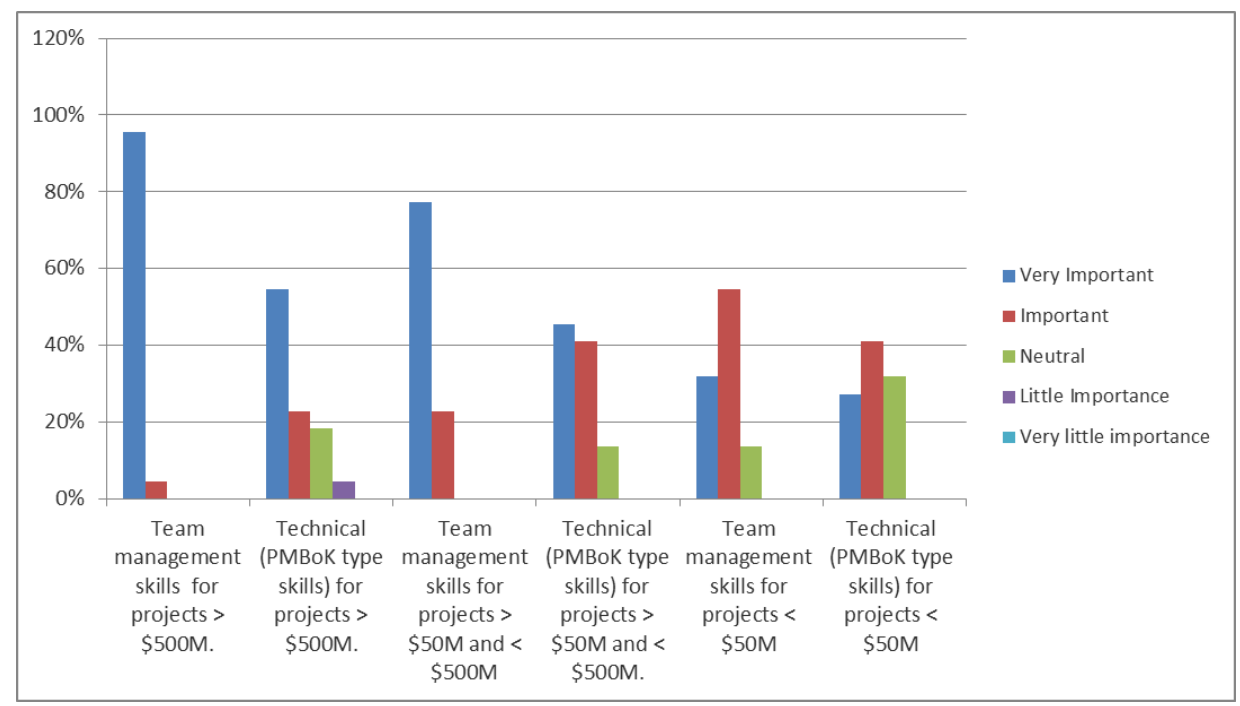

Figure 1: Panel members' views of the relative importance of team management skills and $\mathrm{PMBoK}$ type skills as project size increases.

In the case of PMBoK type skills, when important and very important are considered for projects in the same size range, the respective results were $77 \%$ for projects greater than $\$ 500$ million and $68 \%$ for projects less than $\$ 50$ million. If only the percentage allocated to very important is used, then for project less than $\$ 50$ million a result of $27 \%$ was obtained and for project sizes greater than $\$ 500$ million this percentage increased to $55 \%$.

From the above results, it is obvious that the consensus view of the of panel members is that the need for both PMBoK skills and team management skills increases with project size. The increase in team management skills is significantly more than that of PMBoK skills. However, 
for every size of project the need for team management skills is greater than the need for PMBoK skills. The change in the skill set needed is summarised in one of the respondent's comments.

With the different projects, the problems or specific skills are different. There is a need to learn. As an Engineer, the approach is to technically understand and solve. In a project leadership role, it is not possible to lead by doing and so using the skills, know-how and energies within the team is key Respondent 1.

The Delphi panel's view concerning the increased need for PMBoK type skills as project size increases confirms the work of other researchers (Gowan Jr. and Mathieu, 2005; Papke-Shields, Beise and Quan, 2010) who concluded that larger more complex projects were more likely to use more comprehensive control systems. This increased use is presumably because the managers of such projects rated the need for them as more important.

\section{Panel members' view of the problems resulting from the unique nature of projects identified in the literature}

The respondents' answers to the questions concerning the problems in project management were used to calculate their importance index and the results are presented in Table 6 . The highest-ranking hard skill, development of a working control system, ranked thirteenth. When the twelve issues ranking higher than that of development of a working control system are considered, two out of the top three places were taken by problems relating to scope change with building a cohesive team being an equal second. Of the remaining nine issues, four relate to stakeholder management, four to team management and one to understanding the particular needs of a project.

When all 34 problems areas reported in Table 5 are analysed 64\% of the question categories are found to relate to team management or stakeholder management. Based on this percentage (i.e. $64 \%$ ) the expected number of problems in these categories ranked in the top 13 items of the Relative Importance Index would be 8 rather than 10. The Chi-Squared value with 1 degree of freedom for this result was 0.861 and the two-tailed p-value was 0.354 , indicating that the difference between expected and actual results are not statistically significant.

To test the significance of the rankings of the top 11 items in the Relative Importance Index (there being a tie for $10^{\text {th }}$ place) a Friedman test was performed. The results were: $\chi^{2}(2)=15.572$ and $p=0.113$. Based on this the null hypothesis was accepted leading to the conclusion that the order of the top 11 problems is not statically significant.

However, when the $11^{\text {th }}$ ranked problem is compared to $24^{\text {th }}$ ranked problem $\left(11^{\text {th }}\right.$ from the bottom) using a Wilcoxon test a $p$-value of 0.036 is obtained leading to the rejection of the null hypothesis and to the conclusion that there is a statistically significant difference between the problems ranked in the top 11 items as compared to those problems ranked in the bottom 11 items. To establish the panels' overall view of the significance of the problems Table 5 was used.

Table 5: Significance ratings resulting from the relative importance index result.

\begin{tabular}{|l|l|}
\hline \multicolumn{1}{|c|}{ Relative importance range } & \multicolumn{1}{|c|}{ Result problem rating } \\
\hline 0.8 to 1.0 & Very significant \\
\hline 0.6 to $<0.8$ & Significant \\
\hline 0.4 to $<0.6$ & Neutral \\
\hline 0.2 t o $<0.4$ & Little significance \\
\hline 0.0 to $<0.2$ & Very little significance \\
\hline
\end{tabular}

Table 6, concerning the Relative Importance Index, indicates that the top 10 problems were ranked as very significant. Indeed, it not until the 18th problem that a rating below very significant (and then by 0.01) is given. Based on these figures the panel has confirmed the 
importance of the problems in project management identified from the review of the nature of projects.

Significant comments received from the panel concerning the top five items by Relative Importance Index were as below.

Firstly, with respect to change:

Change is the killer on most major projects. There is a lack of appetite and the mechanisms for change are beavy and readily exploited. I rank "change" as the biggest problem for project delivery. Change to correct technical specification issues, external factors, concessions, options. Usually small in comparison to the contract scope, but they consume us, creating frustration and mistrust. Often the change results from conflicting requirements; client preferential engineering. Contracts with high levels of risk transfer to the contractor increases ambiguity. - Respondent 2.

Secondly, with respect to team building:

Trust and building a cohesive team is strongly influenced by the PMs freedom and ability to secure and empower team members. Often organizational factors, beyond the project have great influence. Also, project health engenders these qualities, but is quick to falter when times get tough. - Respondent 3.

The question leans towards stakeholders being remote or with different cultural or languages. In the absence of good (and open) stakeholder management frameworks, these factors would be very significant. But by recognizing the need for effective management to build a bridge for engagement to overcome the remoteness, culture and language factors these factors can be much reduced. So for me the issue is not location, culture or language, but taking the time to recognize the need to actively manage and keep managing these relationships. It takes time to build relationships and that must be factored into project planning, together with demonstration of respect, collaboration and a less transactional approach. Respondent 4.

In addition, with respect to stakeholder management and communication:

The issues arise from poor facilitation and communication skills of those charged with the stakeholder management. The deeper communication issue is poor skills in seeking the real "agenda" or needs of stakeholders. Professional back.ground issues are prevalent when Clients are investing in a sector they aren't familiar with and don't listen to their advisors. - Respondent 5.

While only ranking 16th by Relative Importance Index the subject of team geographic locations was the subject of several comments, two of these comments are provided below. It is interesting to note that whilst these comments are primarily dealing with the problem of geographic locations they also emphasised the need for good communication:

The problems often arise due to mistaken belief that you can disaggregate the project and the people. I don't see it as cultural per se the designers and construction staff need to intermingle due to the close inseparable link between design and construction and need for both to feed off each other. Two separate teams means two separate project objectives and two different team cultures. A recipe for disaster. Respondent 6

People have a tendency to build teams within their own location, even their own floor or area in the office. Active effort is needed to bring the wider group together - Project culture, values and strong group communications. Local culture (e.g. different countries) and also different disciplines bave cultural resistance. An example is the construction site office which becomes its own project, isolated from the wider project and project goals. - Respondent 7. 
Table 6: Relative Importance Index

\begin{tabular}{|l|r|}
\hline \multicolumn{1}{|c|}{ Problem area } & Relative importance index \\
\hline Lack of a clearly defined project scope & 0.93 \\
\hline Scope changes as the project progresses & 0.92 \\
\hline Building a cohesive team & 0.92 \\
\hline Loss of relationships with key stakeholders & 0.90 \\
\hline Team members' communication needs & 0.90 \\
\hline Understanding the issues involved in the particular project & 0.88 \\
\hline Loss of trust between team members resulting from team changes & 0.88 \\
\hline Stakeholders' personal goals and resultant personal agendas & 0.87 \\
\hline Building trust within the team & 0.85 \\
\hline Loss of a cohesive team & 0.85 \\
\hline Developing rapport with stakeholders & 0.85 \\
\hline Stakeholders' communication needs & 0.83 \\
\hline Developing a working control system & 0.82 \\
\hline Conflicts arising with other stakeholders & 0.81 \\
\hline Obtaining organisational support & 0.81 \\
\hline Team members' different geographic locations & 0.81 \\
\hline Team member changes & 0.80 \\
\hline Unexpected and unforeseen events (e.g. subcontractor goes bankrupt) & 0.80 \\
\hline Managing external stakeholders' expectations & 0.79 \\
\hline Belief that you and the project team can solve the project's problems & 0.79 \\
\hline Conflicts arising with subcontractors & 0.78 \\
\hline Lack of information to make a fully informed decision & 0.77 \\
\hline Changes in the external environment (legislative, economic) & 0.77 \\
\hline Managing internal stakeholders' expectations & 0.76 \\
\hline Conflicts arising internal to the team & 0.74 \\
\hline Conflicts arising external to the team but internal to the parent organisation & 0.73 \\
\hline Team members' cultural backgrounds & 0.72 \\
\hline Team members' personal goals and resultant personal agendas & 0.70 \\
\hline Stakeholders' professional backgrounds & 0.69 \\
\hline Stakeholders' different geographic locations & 0.69 \\
\hline Team members' native language differences & 0.67 \\
\hline Team members' professional backgrounds & 0.65 \\
\hline Stakeholders' cultural backgrounds & 0.65 \\
\hline Stakeholders' native language differences & 0.59 \\
\hline
\end{tabular}

Table 7 presents the mean frequency results. These results should be treated with caution, and rather than regarding the mean frequency of the problems as definitive, particularly those having a mean frequency below $75 \%$ (i.e. average occurrence), they should rather be regarded as establishing that in the panel's collective experience, all of the problems have a reasonable chance of occurring in any given project.

An interesting problem occurring in the top 5 results by mean frequency was that of "Belief that you and the project team can solve the project's problems" and its Relative Importance Index result of 0.79 , placing it in the significant category. The high significance and frequency given to this issue would point to the need for the project manager to have considerable self-confidence (in order to overcome his own self-doubts) and inspirational skills in order to pass that belief on to team members so that they in turn can overcome their doubts. 
Table 7: Problem areas by mean frequency

\begin{tabular}{|c|c|c|}
\hline Problem area & Mean frequency & $\begin{array}{l}\text { Problem frequency } \\
\text { rating }\end{array}$ \\
\hline Team members' communication needs & $79 \%$ & Frequent Occurrence \\
\hline Stakeholders" goals and resultant agendas & $78 \%$ & Frequent Occurrence \\
\hline Understanding the issues involved in the particular project & $74 \%$ & Average Occurrence \\
\hline Scope changes as the project progresses & $73 \%$ & Average Occurrence \\
\hline $\begin{array}{l}\text { Belief that you and the project team can solve the project's } \\
\text { problems }\end{array}$ & $72 \%$ & Average Occurrence \\
\hline 'Team members' different geographic locations & $72 \%$ & Average Occurrence \\
\hline Team member changes & $71 \%$ & Average Occurrence \\
\hline Building a cohesive team & $71 \%$ & Average Occurrence \\
\hline Develop rapport with stakeholders & $71 \%$ & Average Occurrence \\
\hline Managing external stakeholders' expectations & $70 \%$ & Average Occurrence \\
\hline Those arising with subcontractors & $69 \%$ & Average Occurrence \\
\hline Stakeholders' communication needs & $69 \%$ & Average Occurrence \\
\hline Lack of a clearly defined project scope & $68 \%$ & Average Occurrence \\
\hline Lack of information to make a fully informed decision & $65 \%$ & Average Occurrence \\
\hline Building trust within the team & $64 \%$ & Average Occurrence \\
\hline Managing internal stakeholders' expectations & $61 \%$ & Average Occurrence \\
\hline Develop a working control system & $58 \%$ & Average Occurrence \\
\hline Team members' personal goals and resultant personal agendas & $57 \%$ & Average Occurrence \\
\hline Obtain organisational support & $56 \%$ & Average Occurrence \\
\hline Stakeholders' different geographic locations & $56 \%$ & Average Occurrence \\
\hline Team members' cultural backgrounds & $53 \%$ & Average Occurrence \\
\hline Those arising with other stakeholders & $52 \%$ & Average Occurrence \\
\hline Stakeholders' cultural backgrounds & $52 \%$ & Average Occurrence \\
\hline Team members' professional backgrounds & $51 \%$ & Average Occurrence \\
\hline Team members' native language differences & $47 \%$ & Average Occurrence \\
\hline Loss of a cohesive team & $46 \%$ & Average Occurrence \\
\hline Stakeholders' professional backgrounds & $45 \%$ & Average Occurrence \\
\hline Stakeholders' native language differences & $45 \%$ & Average Occurrence \\
\hline Unexpected and unforeseen events & $44 \%$ & Average Occurrence \\
\hline $\begin{array}{l}\text { Conflicts arising externally to the team but internally to the } \\
\text { parent organisation }\end{array}$ & $40 \%$ & Average Occurrence \\
\hline Conflicts arising internally to the team & $39 \%$ & Average Occurrence \\
\hline Loss of trust between team members & $36 \%$ & Average Occurrence \\
\hline Loss of relationship with key stakeholders & $35 \%$ & Average Occurrence \\
\hline Changes in the external environment (legislative, economic) & $29 \%$ & Average Occurrence \\
\hline
\end{tabular}

To reach a better understanding of the impact of the importance of a problem, coupled with its frequency, a Significance Index was used. The index was calculated in a similar manner to Assaf and Al-Hejji (2006) with the mean frequency being used to replace the authors' frequency index. The formula for the Significance Index thus becomes:

\section{Item's Significance Index = Item's mean frequency X Item's Relative Importance Ranking}

Table 8 compares results for top ten problems by Significance Index, rating the results of the same problems obtained using the Relative Importance Index 
Table 8: Comparison of top significance index problems with their position using the relative importance index

\begin{tabular}{|c|l|c|c|}
\hline $\begin{array}{c}\text { Problem } \\
\text { ranking }\end{array}$ & \multicolumn{1}{|c|}{ Problem area } & Significance index & $\begin{array}{c}\text { Retaliative importance } \\
\text { index ranking }\end{array}$ \\
\hline 1 & Team members' communication needs. & 0.71 & 5 \\
\hline 2 & $\begin{array}{l}\text { Stakeholders" goals and resultant } \\
\text { agendas. }\end{array}$ & 0.68 & 12 \\
\hline 3 & Scope changes as the project progresses. & 0.67 & 2 \\
\hline 4 & Building a cohesive team & 0.65 & 3 \\
\hline 5 & Lack of a clearly defined project scope. & 0.63 & 9 \\
\hline 6 & Develop rapport with stakeholders. & 0.61 & 6 \\
\hline 7 & $\begin{array}{l}\text { Understanding the issues involved in } \\
\text { the particular project. }\end{array}$ & 0.59 & 14 \\
\hline 8 & $\begin{array}{l}\text { Team members' differentgeographic } \\
\text { locations. }\end{array}$ & 0.58 & 12 \\
\hline 9 & Stakeholders' communication needs. & 0.57 & 14 \\
\hline 10 & Team member changes. & 0.56 & 1 \\
\hline
\end{tabular}

As can be seen, when frequency is taken into account, the order of the top ten items in the Significance Index is different from that in the Relative Importance Index. The top five items in the Significant Index still contain 4 of the top five from the Relative Importance Index and in addition the top 10 items in the Significance Index are from the top 14 item in the Relative Importance Index. As has been discussed the exact order of items in the top 10 of the Relative Importance Index should not be regarded as statistically significant. It would appear therefore that adjusting for frequency does affect the ranking of the problems but not in any markedly significant way.

\section{Conclusion}

The results of the Delphi study show practising project managers regard the importance of team management skills (soft skills) and PMBoK skills (hard skills) increases as project size increases, and that the rise in the importance of the need for soft skills is more pronounced than the rise in the need for hard skills. All the problems were given a Relative Importance Index score which translates to significant or above (except the last item which fails by 0.01) In addition all the problems were rated by the panel as having at least an average likelihood of occurrence in any given project. Based on this, the importance of the problems in project management identified from a review of the nature of projects was regarded as having been confirmed by the panel. Additionally, but perhaps not surprisingly, the panel found the most significant problems in project management are associated with change resulting from lack of clarity in scope at the start of a project, or changes in scope as the project progresses.

\section{Acknowledgement}

The author would like to thank Adjunct Professor Goran Runeson and Professor Spike Boydell for their assistance in writing this view.

\section{References}

Anantatmula, V.S., 2010. Project manager leadership role in improving project performance. Engineering Management Journal; EMJ, 22(1), p.13.

Assaf, S.A. and Al-Hejji, S., 2006. Cuases of Delay in Large Construction Projects. International journal of project management, 24(4), pp.349-57. doi: http://dx.doi.org/10.1016/j.ijproman.2005.11.010 
Bourne, L. and Walker, D.H., 2004. Advancing project management in learning organizations. Learning Organization, The, 11(3), pp.226-43. doi: http://dx.doi.org/10.1108/09696470410532996

Cramton, C.D. and Webber, S.S., 2005. Relationships among geographic dispersion, team processes, and effectiveness in software development work teams. Journal of Business Research, 58(6), pp.758-65. doi: http://dx.doi.org/10.1016/j.jbusres.2003.10.006

Dalkey, N. and Helmer, O., 1963. An experimental application of the Delphi method to the use of experts. Management science, 9(3), pp.458-67. doi: http://dx.doi.org/10.1287/mnsc.9.3.458

Druskat, V. and Druskat, P., 2012. Applying Emotional Inteligence in the workplace. In: S. Pryke and H. Smyth eds: Wiley-Blackwell.

Du, S.M., Johnson, R.D. and Keil, M., 2004. Project management courses in IS graduate programs: What is being taught? Journal of Information Systems Education, 15, pp.181-8.

Fink, A., 2009. How to conduct surveys: A step-by-step guide: Sage.

Flyvbjerg, B., 2014. What you should know about megaprojects and why: An overview. Project Management Journal, 45(2), pp.6-19. doi: http://dx.doi.org/10.1002/pmj.21409

Geraldi, J., Maylor, H. and Williams, T., 2011. Now, let's make it really complex (complicated): a systematic review of the complexities of projects. International Journal of Operations \& Production Management, 31(9), pp.966-90. doi: http://dx.doi.org/10.1108/01443571111165848

Gonzalez, M.D., 2012. The role of emotional intelligence (ei) in project management over the next five years. International Handbook of Academic Research and Teaching, p.83.

Goodman, R.A. and Goodman, L.P., 1976. Some management issues in temporary systems: A study of professional development and manpower-the theater case. Administrative science quarterly, 21(3), pp.494-501. doi: http://dx.doi.org/10.2307/2391857

Gowan Jr., J. and Mathieu, R.G., 2005. The importance of management practices in IS project performance: An empirical study. Journal of Enterprise Information Management, 18(2), pp.235-55. doi: http://dx.doi.org/10.1108/17410390510579936

Gündüz, M., Nielsen, Y. and Özdemir, M., 2012. Quantification of delay factors using the relative importance index method for construction projects in Turkey. Journal of Management in Engineering, 29(2), pp.133-9. doi: http://dx.doi.org/10.1061/(ASCE)ME.1943-5479.0000129

Hanisch, B. and Wald, A., 2014. Effects of complexity on the success of temporary organizations: Relationship quality and transparency as substitutes for formal coordination mechanisms. Scandinavian Journal of Management, 30(2), pp.197-213. doi: http://dx.doi.org/10.1016/j.scaman.2013.08.005

Hertel, G., Geister, S. and Konradt, U., 2005. Managing virtual teams: A review of current empirical research. Human Resource Management Review, 15(1), pp.69-95. doi: http://dx.doi.org/10.1016/j.hrmr.2005.01.002

Holt, G.D., 2013. Asking questions, analysing answers: relative importance revisited. Construction Innovation: Information, Process, Management, 14(1), pp.2-16.

Keeney, S., McKenna, H. and Hasson, F., 2010. The Delphi technique in nursing and health research: John Wiley \& Sons.

Kometa, S.T., Olomolaiye, P.O. and Harris, F.C., 1994. Attributes of UK construction clients influencing project consultants' performance. Construction Management and Economics, 12(5), pp.433-43. doi: http://dx.doi.org/10.1080/01446199400000053

Lee-Kelley, L. and Sankey, T., 2008. Global virtual teams for value creation and project success: A case study. International journal of project management, 26(1), pp.51-62. doi: http://dx.doi.org/10.1016/j.ijproman.2007.08.010

Likert, R., 1932. A technique for the measurement of attitudes. Archives of psychology.

Linstone, H.A. and Turoff, M., 1979. The Delphi Method: tecniques and applications: Addison-Wesley Massachusetts.

Lundin, R.A. and Söderholm, A., 1995. A theory of the temporary organization. Scandinavian Journal of Management, 11(4), pp.437-55. doi: http://dx.doi.org/10.1016/0956-5221(95)00036-U

MacGregor, S.P., 2005. Achieving Project Management Success Using Virtual Teams. Journal of Product Innovation Management, 22(3), pp.293-5. doi: http://dx.doi.org/10.1111/j.0737-6782.2005.125 1.x

Montoya, M.M., Massey, A.P., Hung, Y.T.C. and Crisp, C.B., 2009. Can You Hear Me Now? Communication in Virtual Product Development Teams*. Journal of Product Innovation Management, 26(2), pp.139-55. doi: http://dx.doi.org/10.1111/i.1540-5885.2009.00342.x

Packendorff, J., 1995. Inquiring into the temporary organization: New directions for project management research. Scandinavian Journal of Management, 11(4), pp.319-33. doi: http://dx.doi.org/10.1016/0956-5221(95)00018-Q

Pant, I. and Baroudi, B., 2008. Project management education: The human skills imperative. International journal of project management, 26(2), pp.124-8. doi: http://dx.doi.org/10.1016/j.ijproman.2007.05.010

Papke-Shields, K.E., Beise, C. and Quan, J., 2010. Do project managers practice what they preach, and does it matter to project success? International journal of project management, 28(7), pp.650-62. doi: http://dx.doi.org/10.1016/j.ijproman.2009.11.002

Parente, F.J., Anderson, J.K., Myers, P. and O'brien, T., 1984. An examination of factors contributing to Delphi accuracy. Journal of Forecasting, 3(2), pp.173-82. doi: http://dx.doi.org/10.1002/for.3980030205

Project Management Institute, 2013. A Guide to the Project Management Body of Knowledge: PMBOK® Guide: Project Management Institute.

Pryke, S. and Smyth, H., 2006. The Management of Complex Projects: A Relationship Approach: Blackwell Publishing. 
Sambasivan, M. and Soon, Y.W., 2007. Causes and effects of delays in Malaysian construction industry. International journal of project management, 25(5), pp.517-26. doi: http://dx.doi.org/10.1016/j.ijproman.2006.11.007

Sankaran, S. and Agarwal, R., 2013.

Skulmoski, G.J., Hartman, F.T. and Krahn, J., 2007. The Delphi method for graduate research. Journal of information technology education, 6, p.1.

SurveyMonkey, SurveyMonkey Inc. . Palo Alto, California, USA, www.surveymonkey.com.

Thomas, J., George, S. and Henning, P.B., 2012. Re-situating expert project managers' praxis within multiple logics of practice. International Journal of managing projects in business, 5(3), pp.377-99.

Turner, J.R. and Müller, R., 2003. On the nature of the project as a temporary organization. International journal of project management, 21(1), pp.1-8. doi: http://dx.doi.org/10.1016/S0263-7863(02)00020-0

Tyssen, A.K., Wald, A. and Spieth, P., 2013. Leadership in Temporary Organisations: A Review of Leadership Theories and a Research Agenda. Project Management Journal, 44(6), pp.52-67. doi: http://dx.doi.org/10.1002/pmi.21380

Verburg, R.M., Bosch-Sijtsema, P. and Vartiainen, M., 2013. Getting it done: Critical success factors for project managers in virtual work settings. International journal of project management, 31(1), pp.68-79. doi: http://dx.doi.org/10.1016/j.ijproman.2012.04.005

Vierimaa, J., 2013. Emotional Intelligence and Project Leadership. Goteborg, Sweden: Chalmers University of Technology. Winch, G.M., 2010. Managing construction projects.: John Wiley \& Sons.

Yeo, K., 1993. Systems thinking and project management- time to reunite. International journal of project management, 11(2), pp.111-7. doi: http://dx.doi.org/10.1016/0263-7863(93)90019-J

i The author has personally managed 3 projects over $\$ 0.5$ billion in size and 2 projects over $\$ 1$ billion. In the smaller type projects managers may effectively manage project on their own while for the larger projects there needs to be a high degree of devolution of decision making. 